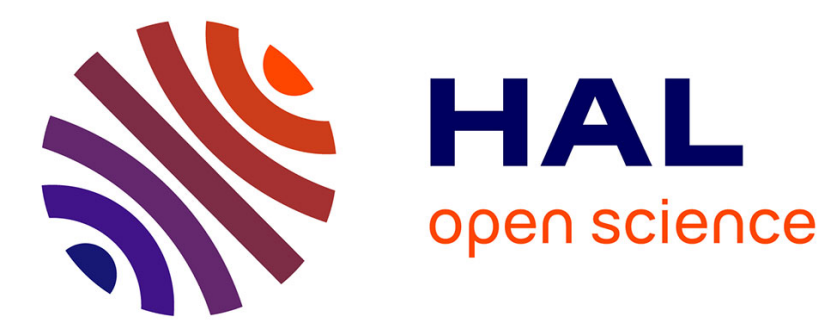

\title{
Risk Factors of Early Kidney Graft Transplantectomy
}

A. Guillaume, V. Queruel, R. Kabore, Karen Leffondre, L. Couzi, K. Moreau, H. Bensadoun, G. Robert, J. M. Ferriere, E. Alezra, et al.

\section{To cite this version:}

A. Guillaume, V. Queruel, R. Kabore, Karen Leffondre, L. Couzi, et al.. Risk Factors of Early Kidney Graft Transplantectomy. Transplantation Proceedings, 2019, 51 (10), pp.3309-3314. 10.1016/j.transproceed.2019.07.027 . hal-03211468

\section{HAL Id: hal-03211468 \\ https://hal.science/hal-03211468}

Submitted on 21 Dec 2021

HAL is a multi-disciplinary open access archive for the deposit and dissemination of scientific research documents, whether they are published or not. The documents may come from teaching and research institutions in France or abroad, or from public or private research centers.
L'archive ouverte pluridisciplinaire HAL, est destinée au dépôt et à la diffusion de documents scientifiques de niveau recherche, publiés ou non, émanant des établissements d'enseignement et de recherche français ou étrangers, des laboratoires publics ou privés.

\section{다)(1) $(5$}

Distributed under a Creative Commons Attribution - NonCommerciall 4.0 International 


\section{RISK FACTORS OF EARLY KIDNEY GRAFT}

\section{TRANSPLANTECTOMY}

\section{Authors:}

Adeline GUILLAUME (a)(d), Vanessa QUERUEL (a), Rémi KABORE (c), Karen LEFFONDRE (c), Lionel COUZI (b), Karine MOREAU (b), Henri BENSADOUN (a), Grégoire ROBERT (a), Jean-Marie FERRIERE (a), Eric ALEZRA (a), Jean-Christophe BERNHARD(a)

(a) Department of Urology and Kidney transplantation, Universitary Hospital of Bordeaux

(b) Department of Nephrology, Universitary Hospital of Bordeaux

(c) Department of statistics, University of Bordeaux

(d) Corresponding author Adeline GUILLAUME - Service d'urologie et de transplantation renale CHU de Bordeaux, place Amelie Raba Léon 33076 Bordeaux, France - Tel number +33556720340 - Fax number +33556795686 - guillaume.adel@gmail.com 


\section{ABSTRACT}

Background: Kidney allograft explant in the first month after transplant is a major concern for medico-surgical teams specialised in kidney transplantation and unacceptable graft loss in the current shortage. The aim of our study was to evaluate the risk factors of early kidney graft explant.

Methods: We retrospectively analysed all adult kidney transplantations performed at our centre from January 2006 to December 2011. Recipient, donor, and transplant characteristics were collected, as well as operating data and early posttiveoperative complications. Univariate and multivariate logistic regression models were used to determine risk factors of early renal allograft explant.

Results: From a total of 707 kidney transplantations, 28 transplantectomies were performed in the first month following transplantation (3.96\%). The average delay was $7.6 \pm 10$ days. Eighty-six per cent of transplantectomies were due to vascular complications. In multivariate analysis, obesity (OR 9.6 [1.63-56.5] p = 0.0007), range of transplantation (OR 36.89 [5.5245] $\mathrm{p}=0.0006)$, intraoperative complication (OR 3.99 [1.22-13] $\mathrm{p}=0.026)$, and early postoperative vascular complication (OR 85.15 [23.6-306] $p<0.0001$ ) were independent risk factors. Neither donors nor graft characteristics were significant.

Conclusion: Early renal graft transplantectomies are rare but count for $50 \%$ of renal graft loss in the first year. Obesity, perioperative complications, and early vascular complications being independent factors associated with early transplantectomies, their prevention should be based on meticulous surgery during procurement, implantation of the kidney, and on the rehabilitation of future recipients.

Keywords: kidney transplantation, surgical complications, graft thrombosis, obesity, atherosclerosis. 


\section{Introduction}

Kidney transplantation (KT) is the ideal treatment of terminal chronic renal failure. Kidneytransplanted patients have better five-year survival (1), a longer life expectancy (2), and a better quality of life (3) than those who remain on dialysis. The economic benefit has already been shown in France and the United States (4).

Despite the promotion of living donations and the extension of the criteria for the deceased donors, graft shortage is still problematic. For example, in France, the number of candidates for grafts keeps increasing; it was 4.9 in 2016 whereas it was 3.5 in 2008. In this context, early graft loss is detrimental. The causes of these failures are difficult to establish; factors involved being manifold, mixing donors and recipients characteristics or perioperative factors. Many studies have reported the incidence and the risk factors for late complications (5)(6)(7), but only a few studies have focused on complications occurring immediately after the surgery (8)(9).

The purpose of this study was to assess the incidence of early kidney graft transplantectomy and to identify the risk factors associated.

\section{Materials and methods}

Study population: We conducted a retrospective cohort study including all adult patients who underwent kidney transplantation (KT) between January 2006 and December 2011 in our regional university transplant centre. Patients $<18$ years old and those with multi-organ transplantations were excluded.

All transplants were performed by senior or junior surgeons sufficiently trained according to the standard surgical techniques for transplantation, with an extraperitoneal approach, 
using a Gibson's incision. Graft vessels were anastomosed end-to-side to the recipient external or common iliac vessels, with prolene $5 / 0$ or $6 / 0$. Urinary anastomosis techniques depended on the surgeon's preference, Lich-Gregoire or Lead-better techniques with or without a Double-J stent, were performed. The bladder catheter was removed seven to ten days after the transplantation, and when it was used, a Double-J stent was removed six weeks later. Doppler ultrasound was systematically performed at day one to verify vascular anastomosis and graft flow. In the postoperative period, recipients were hospitalised in the intensive care urology unit for two or three days, then in the nephrology department.

Data collection: Recipient and donor characteristics, as well as pre and postoperative data were prospectively collected in the transplant database (RAN: réseau aquitain de néphrologie) and in the medical file at the time of transplantation. All data collected were confidential and anonymised. All patients gave their consent for data collection and analyses, and the conduct of this study was approved by the institutional review board (IRB). The primary endpoint was the identification of factors associated with early transplantectomies in our population of adult transplanted patients. An early transplantectomy was defined as the need to remove the kidney within the first month following the graft. All transplantectomies were included regardless of the cause of the malfunction.

The parameters evaluated in this study were:

1) recipient characteristics: age, gender, weight, body mass index (BMI), cause of kidney failure, dialysis modality, time on dialysis, previous transplant, comorbidities (diabetes, smoking, dyslipidaemia), previous abdominal surgery, iliac vessels atherosclerosis evaluated by abdominal tomodensitometry. 
2) donor characteristics: age, gender, cadaveric or living, cause of death, renal function by serum creatinine, number of renal arteries and veins on transplant, and atherosclerosis of graft vessels evaluated during the procurement.

3) perioperative data: duration of intervention, cold ischemia time, graft revascularization time, type of vascular anastomosis (with patch or not), type of urinary anastomosis, vascular complication (difficult bench surgery, vascular injury or thrombosis, repair of anastomoses), blood loss, and medical perioperative complication including haemodynamic instability and respiratory problems.

4) postoperative factors: serum creatinine, delayed graft function (defined as the need for dialysis in the first week), acute rejection, duration of hospitalisation, vascular complications (arterial or venous thrombosis, haemorrhage, other: Doppler anomalies, artery kinking, vascular thrombosis at another place), urinary complications (urinary leaks, haematuria, infection), wound complications (haematoma, dehiscence, abscess), surgical revision and kidney graft explantation.

Statistical analysis: A descriptive analysis of the collected data was conducted in addition to a logistic regression model. Both univariate and multivariate analyses were used to assess the significance of multiple risk factors for early transplantectomy. In univariate analysis, the significant threshold was reached for $p<0.05$. For multivariate analysis, we included in a descending stepwise logistic regression model, candidate variables identified when $p$ was less than 0.02 in the univariate analysis.

Statistical analysis was performed using SAS version 9.3 software (SAS Institute, Cary, NC).

\section{Results}


Of 748 kidney transplantations reported, 707 adult patients were included in the analysis, 25 minors and 16 multi-organ transplants were removed. The mean age of donors and recipients were $50 \pm 16$ and $51 \pm 13$ years, respectively, 46 (6.5\%) of them were living donors, 179 (45\%) grafts had atherosclerosis, and 148 (21\%) of them had multiple arteries. The rest of the population characteristics are presented in Table 1.

Concerning the perioperative data, mean revascularization time was $58 \pm 21 \mathrm{~min}$, and vascular complications occurred in 81 cases (11.5\%) (Table 2$)$.

In the postoperative period, one or more surgical complications occurred in 253 of the 707 patients (35\%). Table 3 presents the details of the postoperative factors for the whole cohort. Early transplantectomy was necessary for 28 patients (3.96\%), with a mean time after surgery of $7.6 \pm 10.5$ days. Three (10.7\%) transplantectomies occurred during the initial surgery and 21 (75\%) during the first week. Twenty-four (86\%) kidneys were explanted for vascular complications: 11 vein thrombosis, eight renal artery thrombosis, four haemorrhagic complications, and one post-stenotic aneurysm. Two kidneys (7\%) were explanted for sepsis, including one secondary to a urinary leak. The last two transplantectomies occurred for acute rejection, and a hepatic malignant tumour was discovered in the donor.

In a multivariate analysis, recipient overweight $(25<\mathrm{BMI}<30)$ or obesity $(\mathrm{BMI}>30)$ were significantly associated with early transplantectomy, multiplying the risk by ten compared to patients with BMI under 25 (OR 9.6 [1.63-56.5]). Patients with one previous KT were more than four times as likely to undergo transplantectomy (OR 4.52 [1.15-17.8]), and the risk was increased by 36 for recipients who received their third kidney or more (OR 36.89 [5.5245]). Both perioperative complications (OR 3.99 [1.22-13]) and vascular postoperative 
complications (OR 85.15 [23.6-306]), including arterial or venous thrombosis and haemorrhage, were related to the transplantectomy (Table 4).

None of the recipients from a living donor had early transplantectomy and there were fewer grafts with multiple arteries in the group who underwent transplantectomy. Graft vessel atherosclerosis was significantly associated with early transplantectomy in the univariate analysis only. Concerning the recipients, age, diabetes, smoking, dyslipidaemia, previous dialysis or atherosclerosis were not associated with transplantectomy.

Five years later, 14 of the 28 patients were transplanted again, and nine were in haemodialysis since the transplantectomy.

\section{Discussion}

In our study we found $10 \%$ of surgical revisions, $11 \%$ of vascular complications, and $19 \%$ of wound complications; these results are in concordance with the literature (7)(10). A lot of studies have analysed the risk factors for surgical complications (8) or for each type of complication (7), but only one had already studied the early transplantectomies and their risk factors (9). A few studies only presented the rate of transplantectomy within the set of surgical complications, rates varying from 1.8 to $4.3 \%$ (7)(8). Englesbe et al. (10) found 14 (2\%) early transplantectomies in the two weeks following the graft within a cohort of 714 kidney transplantations. The risk factors were diabetes of the recipients and older donors. They didn't find any connection with cold ischemia time, multiple renal arteries, or previous transplantation. Even if the risk factors were not the same in our study, the rate of explanted grafts seemed coherent. Ariyarathenam et al. found $4.15 \%$ of early transplantectomies, here again, closer to our result, but the risk factors were not considered (11). 
However, all these studies highlight a close link between allograft explantations and vascular complications, similar to our results. In the cohort by Samhan et al. (12), all the transplantectomies occurred after artery or venous thrombosis; this represented 10 of the 12 transplantectomies in the cohort of Terrier et al. (8) and 13 of the 14 transplantectomies in the cohort of Englesbe et al. (9). In our study, the occurrence of postoperative vascular complication was an independent factor associated with early transplantectomy, although it was more of an aetiology than a risk factor.

One of the first risk factors of vascular complication was atherosclerosis of the recipient, as shown by Hernàndez et al. or Terrier et al. for example (7)(8). This factor was not found in the studies mentioned previously and is not significant in our study, even if only $28 \%$ patients in the group "early transplantectomy" had good vascular status against $41 \%$ in the group "allograft in place".

Secondly, allografts with multiple renal arteries have been controversial. Even if surgeons have long thought that it complicated the surgery (13), recent studies don't confirm this trend, finding no difference in terms of allograft survival and vascular complications (14)(15) (16). Keller et al. concluded their review by saying that multiple renal arteries are a historical risk factor especially thwarted by the surgeon's experience (17). In our study, multiple renal arteries did not increase the risk of transplantectomy, and there were more allograft with multiple renal arteries in the group with "allograft in place" than in the group of early transplantectomy (21.6\% versus 10.7\%). Going from Keller's point of view, in our university hospital, KT with multiple arteries grafts were willingly seniorised to overcome any surgical difficulties. 
Right kidneys are known to be at risk of venous thrombosis but also of artery thrombosis (18). In our study, there were more right kidneys in the group "early transplantectomy" that in the other group (60\% versus $41 \%)$, but the difference was not significant.

Regarding vascular complications, many possible risk factors have been raised in a lot of studies; risk factors commonly accepted are diabetes and thrombophilia of the recipient, haemodynamic instability, and perioperative surgical difficulties, right kidneys, and older donors (17). These data are not significant in our study even if we noted a few trends, as for the right kidneys and atherosclerosis. In all cases, these factors are more and more frequent especially because of the ageing of the population, and right kidneys or with atherosclerosis vessels can't be rejected in the shortage context. Considering the appalling prognosis of vascular complications, it is necessary to prevent them as much as possible. This requires global and optimised support, including:

- meticulous surgical techniques during organ removal, with preparation on the back table, and during the graft,

- reduction of cold ischemia time and use of perfusion machines,

- preservation of the vascular capital of patients on the waiting list (smoking cessation, balanced diet) and evaluation of vascular status and thrombophilia before inscription,

- haemodynamic stability during the surgery and the 48 hours' postoperative,

- use of anticoagulant or antiplatelet treatment, according to the comorbidities of the recipient,

- systematic Doppler ultrasound for early diagnostics of vascular complications in the postoperative period. 
All these approaches aim to reduce the rate of vascular complications and therefore, the rate of early transplantectomy, while adapting to available grafts in the current shortage context.

An interesting finding in our study is the significant association between early transplantectomy and overweight or obesity. This relationship was not found in the study of Englesbe et al. (9). It has been previously established that obesity is a risk factor of surgical complications after adult KT, especially wound complications and surgical site infections (8) (19), but also delayed graft function and lower survival graft (20). Despite this increased risk of surgical complications, the benefit of survival for obese patients with KT has been proved. Glanton et al. showed that KT on obese patients reduced the risk of death by $61 \%$ as compared to obese patients on dialysis (21). In regular practice, it is difficult to appreciate the threshold of BMI beyond which the surgical complications would become higher than the expected benefits of kidney transplantation. At the moment, no scholarly society has established this and practices are heterogeneous in the world. In France, the threshold of 35 $\mathrm{kg} / \mathrm{m} 2$ seems to be usually used, even if the European association of transplantation rather suggests the threshold of $30 \mathrm{~kg} / \mathrm{m} 2$ in the European Renal Best Practice (22). Different values have been mentioned in the literature; $35 \mathrm{~kg} / \mathrm{m} 2$ by Holley, $40 \mathrm{~kg} / \mathrm{m} 2$ by Gill (23), 4and $1 \mathrm{~kg} / \mathrm{m} 2$ by Glanton (21), yet, there is still no consensus on a cut-off of BMI before kidney transplantation.

Here again, multidisciplinary management in the pre-transplant of obese recipients is essential and must contain the patient's education, dietary recommendations, exercise programs, behavioural therapy. In case of failure, the use of bariatric surgery before transplantation is an alternative for patients with $\mathrm{BMI}$ up to $40 \mathrm{~kg} / \mathrm{m} 2$, even if studies are 
missing (24). The use of a robotic technique could yield low complication rates in the obese population, especially wound complications (25)(26).

Concerning the re-transplantations, which are an independent risk factor in our analysis, it is not an established risk factor of surgical or vascular complication. However, Tisserand et al. found $54 \%$ of surgical complications after the second transplantation versus $46 \%$ after the first, but without significant difference (6). In Ojo et al., re-transplantations were a risk factor of graft thrombosis (27). A French report from the biomedicine agency found previous transplantations to be predictive factors of failure at one year. In cases of retransplantation, the surgery is more difficult because the choice of the implantation site is more restricted and the recipient has meanwhile probably deteriorated his vascular status. If a perioperative vascular complication occurs, backup solutions are less available.

All these practical applications can explain the significance of this factor in our study but, in all cases, the range of transplantation is an unchangeable criterion, which cannot contraindicate the inscription on the waiting list in view of the expected benefits of the KT.

This is a retrospective and mono-centre study, which constitutes important limitations. However, we obtained complete information from our databases, which were updated prospectively during the patient's hospitalisations. The main event (early transplantectomy) is rare and, even if we worked in a large cohort with few exclusion criteria, this probably leads to a lack of power in the statistical analysis. Then, some data are missing, not collected in the initial phase (donor BMI, immunological data, and anticoagulant treatment before and after surgery, etc,). 


\section{Conclusion}

Early transplantectomies occur in $4 \%$ of adult $\mathrm{KT}$, mostly due to graft thrombosis, and represent half of the "graft loss" in the first year after transplantation. Obesity and retransplantation are two major and independent risk factors. However, the expected benefits of kidney transplantation in these populations have been proven, medical and surgical teams must give them access to the waiting list. Donor and recipient vascular characteristics are also important factors, increasing the vulnerability to the occurrence of a vascular complication. The knowledge of these data is important and could be applied in our practices, especially during the pre-transplantation assessment with the prevention of obesity and prevention of atherosclerosis, but also with meticulous surgery during the kidney procurement and during the KT to prevent vascular complications. In the current context of shortage, early transplantectomies would deserve future clinical trials to know more accurately how to prevent them.

Conflict of interest statement: none declared.

Funding: No financial support was used for this study 


\section{References}

1. Medin C, Elinder C-G, Hylander B, Blom B, Wilczek H. Survival of patients who have been on a waiting list for renal transplantation. Nephrol Dial Transplant. 5 janv 2000;15(5):701-4.

2. Wolfe RA, Ashby VB, Milford EL, Ojo AO, Ettenger RE, Agodoa LYC, et al. Comparison of Mortality in All Patients on Dialysis, Patients on Dialysis Awaiting Transplantation, and Recipients of a First Cadaveric Transplant. N Engl J Med. 2 déc 1999;341(23):1725-30.

3. Laupacis A, Keown P, Pus N, Krueger H, Ferguson B, Wong C, et al. A study of the quality of life and cost-utility of renal transplantation. Kidney Int. 1 juin 1996;50(1):235-42.

4. Loubeau PR, Loubeau J-M, Jantzen R. The Economics of Kidney Transplantation versus Hemodialysis. Prog Transplant. 1 déc 2001;11(4):291-7.

5. Karam G, Maillet F, Braud G, Battisti S, Hétet JF, Glémain P, et al. Surgical complications in kidney transplantation. Ann Urol. déc 2007;41(6):261-75.

6. Tisserand B, Doré B, Touchard G, Bridoux F, Irani J. Long-term outcome of renal transplantation: impact of surgical complications on graft survival. Prog En Urol J Assoc Fr Urol Société Fr Urol. févr 2013;23(2):113-20.

7. Hernández D, Rufino $M$, Armas $S$, González $A$, Gutiérrez $P$, Barbero $P$, et al. Retrospective analysis of surgical complications following cadaveric kidney transplantation in the modern transplant era. Nephrol Dial Transplant Off Publ Eur Dial Transpl Assoc - Eur Ren Assoc. oct 2006;21(10):2908-15.

8. Terrier N, Long J-A, Bocqueraz F, Cadi P, Boillot B, Bayle F, et al. Surgical complications of renal transplantations: incidence and prognostic factors. Prog En Urol J Assoc Fr Urol Société Fr Urol. déc 2005;15(6 Suppl 1):1271-85. 
9. Englesbe MJ, Punch JD, Armstrong DR, Arenas JD, Sung RS, Magee JC. Single-center study of technical graft loss in 714 consecutive renal transplants. Transplantation. 27 août 2004;78(4):623-6.

10. Pillot P, Bardonnaud N, Lillaz J, Delorme G, Chabannes E, Bernardini S, et al. Risk factors for surgical complications after renal transplantation and impact on patient and graft survival. Transplant Proc. nov 2012;44(9):2803-8.

11. Ariyarathenam A, Bamford A, Akoh JA. Transplant nephrectomy - A single-center experience. Saudi J Kidney Dis Transplant Off Publ Saudi Cent Organ Transplant Saudi Arab. nov 2015;26(6):1108-12.

12. Samhan M, Sinan T, Al-Mousawi M. Vascular complications in renal recipients. Transplant Proc. déc 1999;31(8):3227-8.

13. Lechevallier E, Bretheau D, Berland Y, Olmer M, Rampal M, Coulange C. Outcome of kidney transplants with multiple arteries. Prog En Urol J Assoc Fr Urol Société Fr Urol. juin $1995 ; 5(3): 370-6$.

14. Aydin C, Berber I, Altaca G, Yigit B, Titiz I. The outcome of kidney transplants with multiple renal arteries. BMC Surg. 2004;4:4.

15. Ali-El-Dein B, Osman Y, Shokeir AA, El-Dein ABS, Sheashaa H, Ghoneim MA. Multiple Arteries in Live Donor Renal Transplantation: Surgical Aspects and Outcomes. J Urol. 1 juin 2003;169(6):2013-7.

16. Benedetti E, Troppmann C, Gillingham K, Sutherland DE, Payne WD, Dunn DL, et al. Short- and long-term outcomes of kidney transplants with multiple renal arteries. Ann Surg. avr 1995;221(4):406-14.

17. Keller AK, Jorgensen TM, Jespersen B. Identification of risk factors for vascular thrombosis may reduce early renal graft loss: a review of recent literature. J Transplant 
[Internet]. 2012 http://downloads.hindawi.com/journals/jtran/2012/793461.pdf

18. Phelan PJ, O'Kelly P, Tarazi M, Tarazi N, Salehmohamed MR, Little DM, et al. Renal allograft loss in the first postoperative month: causes and consequences. Clin Transplant. août 2012;26(4):544-9.

19. Marks WH, Florence LS, Chapman PH, Precht AF, Perkinson DT. Morbid obesity is not a contraindication to kidney transplantation. Am J Surg. mai 2004;187(5):635-8.

20. Gore JL, Pham PT, Danovitch GM, Wilkinson AH, Rosenthal JT, Lipshutz GS, et al. Obesity and Outcome Following Renal Transplantation. Am J Transplant. 1 févr 2006;6(2):357-63

21. Glanton CW, Kao T-C, Cruess D, Agodoa LY, Abbott KC. Impact of renal transplantation on survival in end-stage renal disease patients with elevated body mass index. Kidney Int. 2003;63(2):647-653.

22. Group TERBP (ERBP) T guideline development, Abramowicz D, Cochat P, Claas F, Dudley C, Harden P, et al. Guideline. Nephrol Dial Transplant. 8 janv 2013;28(suppl 2):ii1-71. 23. Gill JS, Lan J, Dong J, Rose C, Hendren E, Johnston O, et al. The survival benefit of kidney transplantation in obese patients. Am J Transplant Off J Am Soc Transplant Am Soc Transpl Surg. août 2013;13(8):2083-90.

24. Arias RH, Mesa L, Posada JG, Vélez JP. Kidney transplantation and gastric bypass: a better control of comorbidities. Obes Surg. 2010;20(7):851-854.

25. Breda A, Territo A, Gausa L, Tuğcu V, Alcaraz A, Musquera M, et al. Robot-assisted Kidney Transplantation: The European Experience. Eur Urol. 2018;73(2):273-81.

26. Wagenaar S, Nederhoed JH, Hoksbergen AWJ, Bonjer HJ, Wisselink W, van Ramshorst GH. Minimally Invasive, Laparoscopic, and Robotic-assisted Techniques Versus Open Techniques for Kidney Transplant Recipients: A Systematic Review. Eur Urol. 
2017;72(2):205-17.

27. Ojo AO, Hanson JA, Wolfe RA, Agodoa LY, Leavey SF, Leichtman A, et al. Dialysis modality and the risk of allograft thrombosis in adult renal transplant recipients. Kidney Int. mai 1999;55(5):1952-60. 


\section{Tables}

Table 1 Clinical data of donors, grafts, and recipients

\begin{tabular}{lc}
\hline Variable & \\
\hline Donors characteristics & \\
f Mean age (years) & $49.5 \pm 15.5$ \\
Living donors n(\%) & $46(6.5)$ \\
Cause of death: cerebrovascular/traumatic n(\%) & $392(59) / 138(21)$ \\
Cardiac arrest n(\%) & $164(26.5)$ \\
& \\
\hline Graft characteristics & \\
Right kidney n(\%) & $305(43.5)$ \\
Vessels atherosclerosis n(\%) & $179(45)$ \\
Multiple renal arteries n(\%) & $148(21.2)$ \\
Mean cold ischemia time (Hours) & $16.49 \pm 7.9$ \\
& \\
\hline Recipients characteristics & \\
Mean age (years) & $50.72 \pm 13$ \\
Male n(\%) & $472(67)$ \\
Mean Body mass index (kg/m2) & $24.43 \pm 4.23$ \\
Smoking n(\%) & $282(40.75)$ \\
Dyslipidemia n(\%) & $243(35.12)$ \\
Diabetes n(\%) & $86(12.43)$ \\
Previous transplant: Second graft/>2 n(\%) & $100(14,16) / 24(3.39)$ \\
Type of dialysis: no/haemodialysis/peritoneal dialysis n(\%) & $50(7,23) / 583(82) / 40(6)$ \\
Mean waiting time (month) & $20,47 \pm 25$ \\
Initial nephropathy: glomerular/polycystic/vascular n(\%) & $268(37.9) / 118(16.7) / 60(8,5)$ \\
Vessel atherosclerosis n(\%) & $389(59.4)$ \\
Previous abdominal surgery n(\%) & $466(66.5)$ \\
& \\
\hline
\end{tabular}


Table 2 Peroperative factors

\begin{tabular}{lc}
\hline Variable & \\
\hline Mean revascularization time (min) & $57.9 \pm 21$ \\
Lich Gregoir urinary anastomosis $\mathrm{n}(\%)$ & $392(69)$ \\
Double-J stent $\mathrm{n}(\%)$ & $531(80)$ \\
Mean blood loss (ml) & $270.45 \pm 253$ \\
& \\
\hline Transfusion $\mathrm{n}(\%)$ & $26(3.68)$ \\
Vascular complication $\mathrm{n}(\%)$ & $81(11.45)$ \\
Medical complication $\mathrm{n}(\%)$ & $10(1.41)$ \\
Transplantectomy $\mathrm{n}(\%)$ & $3(042)$ \\
\hline
\end{tabular}

Table 3 Post-transplant factors (in the first month)

\begin{tabular}{lc}
\hline Variable & \\
\hline Mean hospitalisation time (days) & $17 \pm 10$ \\
\hline Reintervention $\mathrm{n}(\%)$ & $70(9.97)$ \\
Transplantectomy $\mathrm{n}(\%)$ & $28(3.96)$ \\
Wound complications n(\%) & $137(19.49)$ \\
$\quad$ Per-graft hematoma & $88(12)$ \\
Vascular complications n(\%) & $79(11.17)$ \\
Renal artery thrombosis & $13(1.8)$ \\
Vein thrombosis & $13(1.8)$ \\
Haemorrhage & $4(., 6)$ \\
Other n(\%) & $49(7)$ \\
Urinary leak n(\%) & $14(2)$ \\
\hline Medical complications n(\%) & $322(45)$ \\
Delayed graft function $\mathrm{n}(\%)$ & $227(32.5)$ \\
Acute rejection $\mathrm{n}(\%)$ & $75(10.7)$ \\
\hline Death n(\%) & $4(0.5)$ \\
\hline
\end{tabular}


Table 4 Risk factors for early transplantectomy

\begin{tabular}{|c|c|c|c|c|c|}
\hline \multirow[t]{2}{*}{ Risk factor } & \multicolumn{3}{|c|}{ Univariate analysis } & \multicolumn{2}{|c|}{ Multivariate analysis } \\
\hline & $\begin{array}{c}\text { Patients with } \\
\text { transplantectomy } \\
\begin{array}{c}(\%) \\
\mathrm{N}=28\end{array}\end{array}$ & $\begin{array}{l}\text { Patients with } \\
\text { functional graft } \\
\begin{array}{c}(\%) \\
N=679\end{array}\end{array}$ & $p$-value & OR $(95 \% \mathrm{Cl})$ & $p$-value \\
\hline \multicolumn{6}{|l|}{ BMI (kg/m2) } \\
\hline$<25$ & $9(32)$ & $416(61)$ & & 1 & \\
\hline $25-30$ & $15(54)$ & $202(30)$ & 0.013 & $10.43(3.07-35.4)$ & 0.0007 \\
\hline$>30$ & $4(14)$ & $61(9)$ & & $9.6(1,63-56.5)$ & \\
\hline \multicolumn{6}{|l|}{ Previous transplant } \\
\hline None & $18(64)$ & $564(83)$ & & 1 & \\
\hline Second & $6(21)$ & $94(14)$ & 0.044 & 4.52 (1.15-17.8) & 0.0006 \\
\hline$>2$ & $4(14)$ & $21(3)$ & & $36.9(5.55-245)$ & \\
\hline $\begin{array}{l}\text { Atherosclerosis } \\
\text { renal artery }\end{array}$ & $15(68)$ & $264(41)$ & 0.014 & - & NS \\
\hline $\begin{array}{l}\text { Perioperative } \\
\text { complication }\end{array}$ & $11(39)$ & $77(11)$ & 0.001 & $3,99(1.2-213)$ & 0,02 \\
\hline \multicolumn{6}{|l|}{$\begin{array}{l}\text { Postoperative } \\
\text { complications }\end{array}$} \\
\hline Haematoma & $9(36)$ & $79(12)$ & 0.0008 & - & NS \\
\hline Wound complication & $11(44)$ & $126(19)$ & 0.003 & - & NS \\
\hline $\begin{array}{l}\text { Vascular } \\
\text { complication }\end{array}$ & $21(84)$ & $59(9)$ & 0.0001 & $85(23.6-306)$ & 0,0001 \\
\hline
\end{tabular}

